\title{
Severe blunt thoracic trauma: Differences between adults and children in a level I trauma centre
}

\author{
D L Skinner, ${ }^{1} \mathrm{MB}$ ChB, FCS (SA), MMed; D den Hollander, ${ }^{2} \mathrm{MB}$ ChB, FCS (SA), Cert Trauma (SA), MPhil; \\ G L Laing, ${ }^{2}$ MB ChB, FCS (SA), Cert Trauma (SA); R N Rodseth, ${ }^{1,3}$ MB ChB, FCA (SA), MMed, Cert Crit Care (SA), MSc, PhD; \\ D J J Muckart, ${ }^{2,4}$ FRCS, MMedSc, FCCM (SA), ACS (SA)
}

\begin{abstract}
${ }^{1}$ Department of Anaesthetics and Critical Care, Nelson R Mandela School of Medicine, College of Health Sciences, University of KwaZulu-Natal, Durban, South Africa

${ }^{2}$ Department of Surgery, Nelson R Mandela School of Medicine, College of Health Sciences, University of KwaZulu-Natal, Durban, South Africa

${ }^{3}$ Population Health Research Institute, Hamilton, Canada, and Department of Outcomes Research, Cleveland Clinic, Cleveland, Ohio, USA

${ }^{4}$ Department of Trauma Surgery: Level I Trauma Unit and Trauma Intensive Care, Inkosi Albert Luthuli Central Hospital, Durban, South Africa
\end{abstract}

Corresponding author: D L Skinner (drdavidskinner@gmail.com)

\begin{abstract}
Background. Trauma is a leading cause of death in the developing world. Blunt thoracic trauma represents a major burden of disease in both adults and children. Few studies have investigated the differences between these two patient groups.

Objective. To compare mechanism of injury, presentation, management and outcome in children and adults with blunt thoracic trauma. Methods. Patients were identified from the database of the trauma intensive care unit at Inkosi Albert Luthuli Central Hospital, Durban, South Africa. Demographics and relevant data were extracted from a pre-existing database.

Results. Of 415 patients admitted to the unit, 331 (79.7\%) were adults and 84 (20.2\%) children aged $<18$ years. The median injury severity score (ISS) was similar for both age groups $(32 \mathrm{v} .34 ; p=0.812)$. Adults had a higher lactate level at presentation $(3.94 \mathrm{v} .2 .60 \mathrm{mmol} / \mathrm{L}$; $p=0.001$ ). Of the children, $96.4 \%$ were injured in motor vehicle collisions, $75.0 \%$ as pedestrians. Compared with adults, children had significantly fewer rib fractures $(20.2 \%$ v. $42.0 \%$; $p<0.001)$, flail chests $(2.4 \%$ v. $26.3 \%$; $p<0.001)$ and blunt cardiac injuries (BCIs) $(9.5 \% \mathrm{v}$. $23.6 \% ; p=0.004)$, but sustained more lung contusions $(79.8 \%$ v. $65.6 \% ; p=0.013)$. Mortality in children was significantly lower than in adults ( $16.7 \%$ v. $27.8 \% ; p=0.037)$.

Conclusion. Thoracic injuries in children are the result of pedestrian collisions more often than in adults. They suffer fewer rib fractures and BCIs, but more lung contusions. Despite similar ISSs, children have significantly lower mortality than adults. More effort needs to be concentrated on child safety and preventing pedestrian injury.

S Afr Med J 2015;105(1):47-51. DOI:10.7196/SAMJ.8499
\end{abstract}

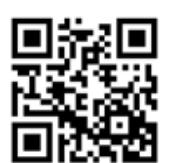

Trauma is a leading cause of death in the developing world, and represents a major burden of disease in South Africa (SA) ${ }^{[1,2]}$ Children are disproportionately affected ${ }^{[3]}$ Blunt trauma secondary to motor vehicle collisions (MVCs) contributes to the majority of admissions to trauma centres. ${ }^{[4]}$ Significant blunt thoracic trauma in both adults and children requires advanced imaging and critical care support that places strain on a resource-limited healthcare system.

Paediatric trauma from MVCs is often multisystem, with a high incidence of thoracic involvement. ${ }^{[5]}$ Paediatric blunt thoracic trauma presents difficulties in both diagnosis and management owing to differences in anatomy. ${ }^{[6]}$ Initial investigations may not reveal significant axial skeletal damage despite high energy transfer and resultant lung contusion, because of the elastic nature of the child's chest wall. Associated injuries such as rib and sternal fractures are thought to occur less commonly in the paediatric population. Importantly, their absence does not indicate lesser severity of injury.

Few articles have investigated the differences in injury pattern between adult and paediatric populations. ${ }^{[6-11]}$ We aimed to review and contrast the incidence and outcome of blunt thoracic trauma among adults and children in a single level I trauma centre over a 6-year period.

\section{Methods}

We conducted a retrospective observational study of patients admitted to the trauma intensive care unit (TICU) at Inkosi Albert Luthuli Central Hospital (IALCH), Durban, KwaZulu-Natal Province, SA, from March 2007 to March 2013. This 10-bed unit admits critically injured patients and serves a drainage area with a population of approximately 11 million. Admissions are either directly from the scene of the incident, or inter-hospital transfers (IHTs) from a facility lacking the necessary imaging modalities or intensive care facilities to manage the patient. All patients who are admitted to the TICU are stabilised in a resuscitation area and any necessary imaging or surgical procedures are performed before admission to the unit.

We included all patients presenting to the unit with blunt chest trauma, either in isolation or as part of multiple system injury, irrespective of age. Children were defined as any patient $<18$ years of age. We excluded patients with penetrating thoracic injuries or blunt injury with no thoracic trauma, and those declared dead on arrival at the resuscitation area.

The trauma unit database and hospital information systems (Medicom and Soarian) were used to retrieve patient data for this analysis. We extracted: (i) patient demographics: age, gender, mechanism of injury, injury severity score (ISS) and site of referral (scene or IHT); (ii) initial lactate value; (iii) presence of rib fractures (single and multiple fractures were included), pulmonary contusion, flail segments, sternal fracture or blunt aortic injury; (iv) other system injuries, which were divided into head, face, spine, abdomen, limb (either single or multiple) and external; ( $v$ ) length of stay in the TICU; and $(v i)$ in-hospital mortality and cause of death.

A pulmonary contusion was defined as the presence of typical lung parenchymal changes on computed tomography (CT) with the presence 
of hypoxaemia. A flail chest was defined as two or more rib fractures at two or more places; patients classified as having sustained a flail chest were not included in the rib fracture group.

Blunt cardiac injury (BCI) was defined as the presence of blunt thoracic trauma combined with an elevated serum troponin level; clinical findings of pericardial rupture, cardiac herniation or central tendon rupture; hypotension requiring inotropic support not explained by haemorrhagic, septic or neurogenic shock; and electrocardiographic (ECG) abnormalities or transthoracic echocardiography findings in keeping with BCI. ECG changes recorded included atrial or ventricular dysrhythmias, ST-segment elevation or depression, T-wave inversion or conduction abnormalities. Echocardiography findings recorded included regional wall motion abnormalities, paradoxical septal wall motion, septal wall defects, pericardial collections, chordal or valve rupture, and aortic root dissection.

Patients were stabilised either in theatre or in the resuscitation unit before transfer to the TICU. The need for further imaging was evaluated in all patients and CT scans were performed for suspected great-vessel injury and to identify other system injuries, unless contraindicated. Analgesia was provided in the form of intravenous opiates or paracetamol. Patients with isolated thoracic injuries not requiring mechanical ventilation received regional analgesia in the form of either a thoracic epidural or a paravertebral block.

The primary aim of this study was to examine the outcomes of critically ill patients with blunt thoracic trauma in terms of TICU mortality and length of stay in the unit. A secondary aim was to describe the types of thoracic trauma in both children and adults and to document their differences.

\section{Statistics}

Means (standard deviations (SDs)) are reported for normally distributed data, and medians and interquartile ranges (IQRs) for

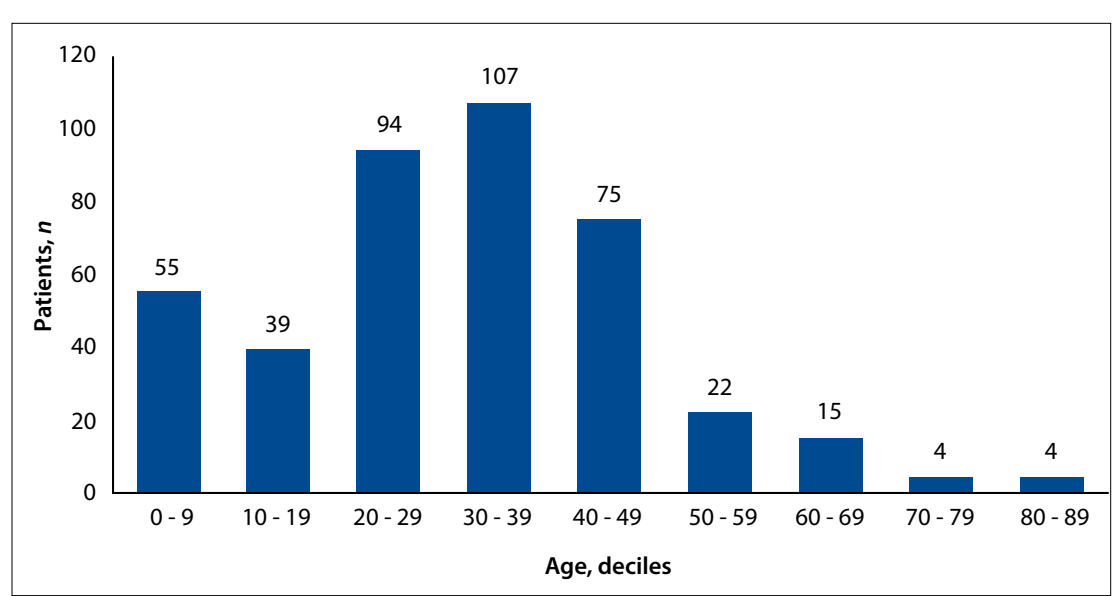

Fig. 1. Age distribution of all patients.

data not normally distributed. Ranges are reported for all ages. The $\chi^{2}$ test or Fisher's exact test were used for categorical data, and Student's $t$-test and the Mann-Whitney $U$-test for continuous data where appropriate. A $p$-value of $<0.05$ was considered significant.

\section{Results}

Over the 6-year period, 415 patients were admitted with blunt thoracic trauma. Of these 84 were children, of whom 55 were $<10$ years of age (Fig. 1). While males predominated overall, there were fewer males in the paediatric group. ISSs were similar in the paediatric and adult groups (median 34 (IQR 25 - 41) v. 32 (24 - 41);

Table 1. The demographics of patients admitted to the TICU with blunt chest trauma, $2007-2013$

\begin{tabular}{|c|c|c|c|c|}
\hline Demographics & Total population & Adult ( $\geq 18$ years) & Paediatric $(<18$ years $)$ & $p$-value \\
\hline Patients, $n(\%)$ & $N=415$ & $331(79.8)$ & $84(20.2)$ & \\
\hline Age (years), mean (SD), range & $30.2(16.2), 2-84$ & $36.6(12.9), 18-84$ & $8.40(4.1), 2-17$ & \\
\hline Male gender, $n(\%)$ & $N=293$ & $244(73.7)$ & $49(58.3)$ & $0.007^{*}$ \\
\hline ISS, median (IQR) & $32(24-41)$ & $32(24-41)$ & $34(25-41)$ & 0.812 \\
\hline Referral from scene, $n(\%)$ & $105(25.3)$ & $86(26.0)$ & $19(22.6)$ & 0.576 \\
\hline $\begin{array}{l}\text { Presentation lactate level }(\mathrm{mmol} / \mathrm{L}) \text {, } \\
\text { mean }(\mathrm{SD})\end{array}$ & $3.67(3.36)$ & $3.94(3.6)$ & $2.60(2.1)$ & $0.001^{*}$ \\
\hline
\end{tabular}

Table 2. Mechanism of injury

\begin{tabular}{|c|c|c|c|c|}
\hline Mechanism, $n(\%)$ & $\begin{array}{l}\text { Total population } \\
(N=415\end{array}$ & $\begin{array}{l}\text { Adult }(\geq 18 \text { years }) \\
(n=331)\end{array}$ & $\begin{array}{l}\text { Paediatric ( }<18 \text { years }) \\
(n=84)\end{array}$ & $p$-value \\
\hline MVC pedestrian & $187(45.1)$ & $124(37.5)$ & $63(75.0)$ & $<0.001^{\star}$ \\
\hline MVC passenger & $117(28.2)$ & $100(30.2)$ & $17(20.2)$ & 0.078 \\
\hline MVC driver & $72(17.4)$ & $71(21.5)$ & $1(1.2)$ & $<0.001^{*}$ \\
\hline Structure collapse/blunt trauma NOS & $17(4.1)$ & $15(4.5)$ & $2(2.4)$ & 0.542 \\
\hline Motorcycle & $12(2.9)$ & $12(3.6)$ & $0(0)$ & 0.136 \\
\hline Fall & $10(2.4)$ & $9(2.7)$ & $1(1.2)$ & 0.694 \\
\hline
\end{tabular}


$p=0.812$ ), although the mean (SD) lactate level at presentation was significantly lower in the paediatric population $(2.60(2.06) \mathrm{v}$. 3.94 (3.57); $p=0.001$ ) (Table 1).

The commonest mechanism of injury was an MVC, accounting for $93.5 \%$ of admissions. The majority of children (75.0\%) were injured in pedestrian MVCs. Not surprisingly, there were significantly more adults in the MVC driver category. Very few patients had injuries from structure collapse, assaults, motorcycle accidents or falls (Table 2).

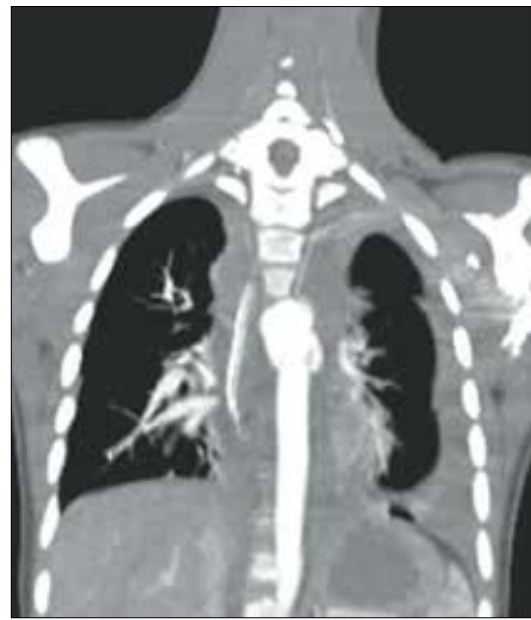

Fig. 2. CT scan, coronal view, showing rupture of the descending aorta in an 11-year-old child. (CT = computed tomography.)
The thoracic injuries seen across the whole group consisted predominantly of pulmonary contusions (68.4\%), rib fractures $(38.1 \%)$ and a surprisingly high number of flail chests $(21.4 \%)$ and BCIs (20.7\%). Sternal fracture was uncommon, with an incidence of $3.1 \%$. Only one child $(1.2 \%)$ sustained a blunt thoracic aortic injury, which required repair under bypass by the cardiothoracic surgical service (Figs 2 and 3). The incidence of pulmonary contusion was highest in the paediatric

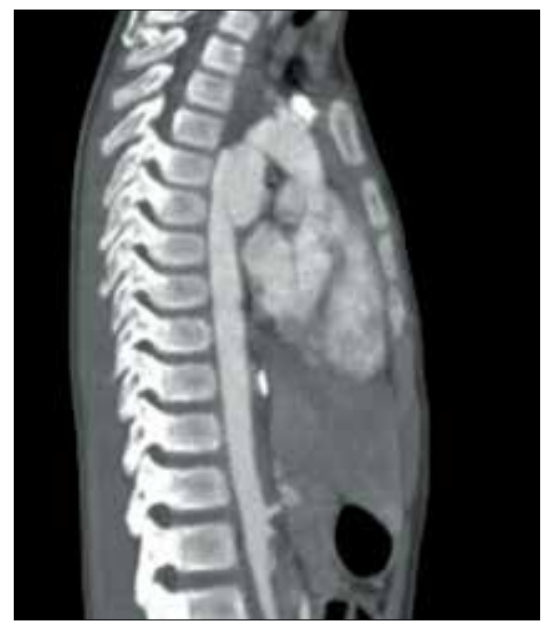

Fig. 3. CT scan, sagittal view, showing rupture of the descending aorta in the same child. (CT = computed tomography.) group, while rib fractures, flail chests and BCIs predominated in the adult group (Table 3).

Among the patients with multiple system injuries, head injuries predominated in the paediatric group (61.9\% v. $42.3 \%$; $p<0.001)$, while spinal injuries predominated in the adult group $(20.2 \%$ v. $2.9 \% ; p<0.001)$ (Table 4). Only 31 patients were admitted with isolated thoracic trauma, the majority of patients sustaining injury to two or more systems (Table 5).

The overall mortality rate was $25.5 \%$, but the rate was significantly lower in the paediatric group than in the adult group ( $16.7 \%$ v. $27.8 \% ; p=0.037)$. Length of stay in the TICU was similar in the two groups, with no statistically significant difference (Table 6). There was a significantly higher number of deaths from traumatic brain injury in the paediatric group (42.9 v. $15.2 \% ; p=0.024)$. There were no significant differences in deaths from thoracic or septic complications between adults and children.

\section{Discussion}

Death and disability from trauma in SA is endemic and has been termed the 'malignant epidemic' in previous publications. ${ }^{[1,2]} \mathrm{SA}$ has a road traffic accident mortality rate of 10.39/100 000 people, according to a study done from 2001 to 2006 , with the

Table 3. Spectrum of thoracic injuries in blunt thoracic trauma

\begin{tabular}{|c|c|c|c|c|}
\hline Injury, $\boldsymbol{n}(\%)$ & $\begin{array}{l}\text { Total population } \\
(N=415)\end{array}$ & $\begin{array}{l}\text { Adult }(\geq 18 \text { years }) \\
(n=331)\end{array}$ & $\begin{array}{l}\text { Paediatric }(<18 \text { years }) \\
(n=84)\end{array}$ & $p$-value \\
\hline Rib fractures & $158(38.1)$ & $141(42.0)$ & $17(20.2)$ & $<0.001^{\star}$ \\
\hline Flail chest & $89(21.4)$ & $87(26.3)$ & $2(2.4)$ & $<0.001^{*}$ \\
\hline Blunt aortic injury & $16(3.9)$ & $15(4.5)$ & $1(1.2)$ & 0.212 \\
\hline Sternal fracture & $13(3.1)$ & $13(3.9)$ & $0(0)$ & 0.080 \\
\hline Blunt cardiac injury & $86(20.7)$ & $78(23.6)$ & $8(9.5)$ & $0.004^{*}$ \\
\hline Pulmonary contusion & $284(68.4)$ & $217(65.6)$ & $67(79.8)$ & $0.013^{*}$ \\
\hline
\end{tabular}

Table 4. Body regions injured other than thorax

\begin{tabular}{|c|c|c|c|c|}
\hline Body region, $n(\%)$ & $\begin{array}{l}\text { Total population } \\
(N=415\end{array}$ & $\begin{array}{l}\text { Adult }(\geq 18 \text { years }) \\
(n=331)\end{array}$ & $\begin{array}{l}\text { Paediatric }(<18 \text { years }) \\
(n=84)\end{array}$ & $p$-value \\
\hline Head & $192(46.8)$ & $140(42.3)$ & $52(61.9)$ & $0.001^{*}$ \\
\hline Face & $61(14.7)$ & $50(15.1)$ & $11(13.1)$ & 0.732 \\
\hline Abdomen & $137(33.0)$ & $104(31.4)$ & $33(39.3)$ & 0.194 \\
\hline $\operatorname{Limb}(s)$ & $266(64.1)$ & $218(65.9)$ & $48(57.1)$ & 0.161 \\
\hline Spine & $69(16.6)$ & $67(20.2)$ & $2(2.4)$ & $<0.001^{\star}$ \\
\hline External & $54(13.0)$ & $40(12.1)$ & $14(16.7)$ & 0.277 \\
\hline
\end{tabular}


Table 5. Number of body regions injured in addition to thoracic injury

\begin{tabular}{|c|c|c|c|c|}
\hline Body regions $(N), n(\%)$ & $\begin{array}{l}\text { Total population } \\
(N=415)\end{array}$ & $\begin{array}{l}\text { Adult }(\geq 18 \text { years }) \\
(n=331)\end{array}$ & $\begin{array}{l}\text { Paediatric }(<18 \text { years }) \\
(n=84)\end{array}$ & $p$-value \\
\hline 0 - isolated chest & $31(7.5)$ & $24(7.3)$ & $7(8.3)$ & 0.816 \\
\hline 1 & $118(28.4)$ & $96(29.0)$ & $22(26.2)$ & 0.685 \\
\hline 2 & $153(36.9)$ & $123(37.2)$ & $30(35.7)$ & 0.899 \\
\hline 3 & $95(22.9)$ & $73(22.1)$ & $22(26.2)$ & 0.467 \\
\hline 4 & $17(4.1)$ & $14(4.2)$ & $3(3.6)$ & 1.000 \\
\hline 5 & $1(0.2)$ & $1(0.30)$ & $0(0)$ & 1.000 \\
\hline
\end{tabular}

Table 6. Outcomes of patients with blunt thoracic injury

\begin{tabular}{|c|c|c|c|c|}
\hline Outcome & $\begin{array}{l}\text { Total population } \\
(N=415)\end{array}$ & $\begin{array}{l}\text { Adult }(\geq 18 \text { years }) \\
(n=331)\end{array}$ & $\begin{array}{l}\text { Paediatric }(<18 \text { years }) \\
(n=84)\end{array}$ & $p$-value \\
\hline Overall mortality, $n(\%)$ & $106(25.5)$ & $92(27.8)$ & $14(16.7)$ & $0.037^{\star}$ \\
\hline Length of stay, median (IQR) & $11(6-16)$ & $11(6-19)$ & $12(6-19)$ & 0.400 \\
\hline
\end{tabular}

peak occurring among young males aged 35 - 49 years. A significant number of children are injured by MVCs: 3.89/100 000 in the $0-14$-year age group, rising to $9.33 / 100000$ in the $15-24$ age group. ${ }^{[12]}$ Paediatric trauma has been referred to as 'the neglected childhood killer disease', having significant social, economic and health system impact. ${ }^{[13]}$

In our study, the vast majority of adults and children sustained complex multiple system trauma during MVCs, isolated blunt thoracic trauma being rare. The facilities required to manage such patients are scarce in a resource-constrained healthcare system. Paediatric trauma from pedestrian MVCs is highly preventable.

This study highlights the ongoing challenges faced by emergency care personnel in SA. These include dealing with the high incidence of paediatric trauma, in the face of a relative lack of resources designated specifically for injured children. Shortages in staffing, combined with the high workload experienced in many SA emergency departments, place a great burden on personnel involved in paediatric trauma care. This burden is further exacerbated by the psychological and emotional impact of dealing with severely injured children on a regular basis.

Blunt thoracic trauma has rarely been studied in the paediatric population. ${ }^{[6-11]}$ Injury patterns are thought to differ between adults and children. ${ }^{[14,15]}$ Our study indeed shows that children are far more likely than adults to sustain head injury together with their thoracic trauma. This finding is probably explained by the proportionally

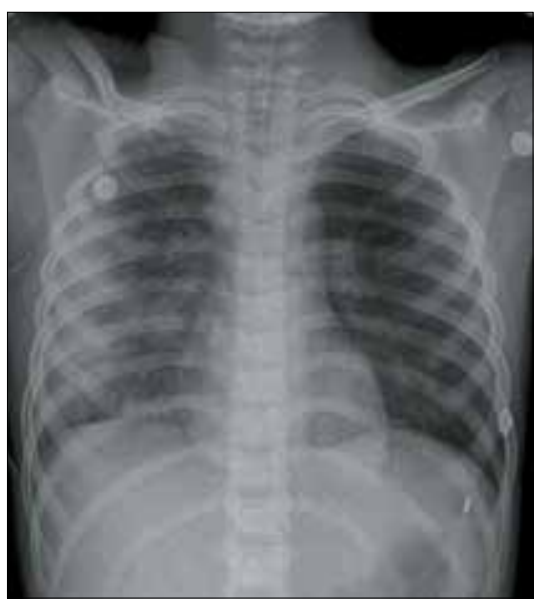

Fig. 4. Supine chest radiograph of a 7-year-old child with blunt thoracic trauma on admission to the TICU. (TICU = trauma intensive care unit.)

larger head/thoracic ratio in children and their higher incidence of injury in pedestrian MVCs. Children travelling as passengers also remain a vulnerable group: in a recent study, Van Hoving et al. ${ }^{[16]}$ showed a very low rate of seatbelt use among child passengers in the Cape Town metropole, with compliance as low as $14.4 \%$.

BCI in children is relatively underdiagnosed, owing to difficulties in diagnosis and a lack of clinical suspicion. ${ }^{[17,18]}$ We applied clinically relevant criteria to the diagnosis of BCI and found a surprisingly high incidence of $9.5 \%$. This highlights the need for a high index of suspicion for BCI in children with blunt thoracic injuries and other potentially distracting injuries. The long-term sequelae of this injury remain a subject for further investigation.

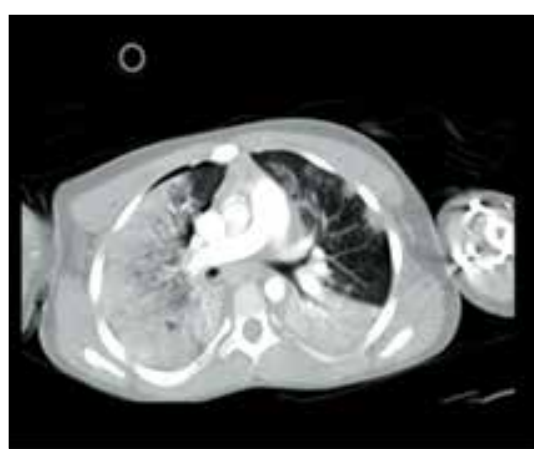

Fig. 5. Axial chest CT scan of the same 7-yearold child, showing extensive bilateral pulmonary contusions and a small anterior pneumothorax not evident on the supine chest radiograph. (CT = computed tomography.)

Blunt vascular injuries are believed to be uncommon in children, as we found in our patients, but are potentially life threatening.

Pulmonary contusions are similarly notoriously difficult to diagnose. The increased skeletal compliance and absence of rib fractures can make this diagnosis in children particularly difficult. Conventional $\mathrm{X}$-ray imaging can be misleading and the severity of lung contusion unappreciated, especially immediately after the injury, as shown in Figs 4 and 5. In our study, the paediatric group had fewer rib fractures (20.2\%) and flail chests (2.4\%) than the adult group, but had a far higher incidence of pulmonary contusion $(79.8 \%$ v. $65.6 \%$; $p=0.013)$. This emphasises the fact that absence of rib fractures in injured children does not signal absence of underlying lung contusion, in keeping with other authors' experience. $^{[7]}$ 
There was a significantly lower mortality rate in the paediatric group ( $16.7 \%$ v. $27.8 \%$; $p=0.037$ ), despite ISSs in the two groups being similar. This lower mortality contrasts with other authors' experience. Allen et al. ${ }^{[18]}$ found no difference in mortality between adult and paediatric patients. The overall mortality in the paediatric group of $16.7 \%$ is in keeping with other studies of paediatric thoracic trauma. ${ }^{[6-9]}$

Although there was no difference in referral types (i.e. referral from the scene, with little or no resuscitation initiated, or IHT, with prior stabilisation), there was a significantly lower baseline lactate level in the paediatric group. Children have a greater ability to compensate for trauma-related shock than adults, with hypotension appearing as a late sign of hypovolaemic shock. ${ }^{[20]}$ The difference in lactate levels between the adult and paediatric groups is not easily explained, as the two groups had similar injury severity. Discrepancies in lactate production between children and adults following trauma have not been adequately investigated or reported in the literature, and further research is needed to examine whether this difference is a result of differing compensatory mechanisms in shock.

A review of the activity of the Johannesburg Hospital Trauma Unit conducted over a 17-year period from 1985 to 2001 revealed an increase in the volume of paediatric trauma, the majority of injuries in the 5 - 14-year age group occurring in pedestrian MVCs. ${ }^{[2]}$ This is replicated in our experience, with $13.2 \%$ of our patients having been under the age of 10 years. Further efforts by government programmes and non-governmental organisations to raise awareness of child safety among parents and older children are urgently required.

\section{Study limitations}

The study was performed in a single centre that serves a large heterogeneous population. Patients admitted to the TICU are often severely injured, thus skewing the overall profile of the patients towards those with more severe injuries.

The referral vascular surgery service in KwaZulu-Natal is situated in the same hospital (IALCH) as the TICU, and as a number of patients with aortic injuries were referred specifically for investigation and treatment by IALCH's vascular team, the number of patients seen with aortic injury may have been increased.

\section{Conclusion}

The burden of adult and paediatric trauma in SA remains unacceptably high. Thoracic injuries are the result of pedestrian collisions more often in children than in adults. Children suffer fewer rib fractures and less blunt cardiac injury, but more lung contusions. Children's thoracic injuries are more often associated with head injuries and less often with spine injuries than is the case in adults. Children have a significantly lower mortality than adults, despite similar ISSs. Notably, the majority of paediatric deaths were secondary to traumatic brain injury rather than thoracic injury.

More effort needs to be concentrated on injury prevention and child safety, especially road safety and pedestrian supervision.

\section{References}

1. Muckart DJ. Trauma - the malignant epidemic. S Afr Med J 1991;79(2):93-95.

2. Bowley DM, Khavandi A, Boffard KD, et al. The malignant epidemic - changing patterns of trauma. $S$ Afr Med J 2002;92(10):798-802.

3. Van As AB. Paediatric trauma care. African Journal of Paediatric Surgery 2010;7(3):129-133. [http:// dx.doi.org/10.4103/0189-6725.70409]

4. Veysi VT, Nikolaou VS, Paliobeis C, Efstathopoulos N, Giannoudis PV. Prevalence of chest trauma, associated injuries and mortality: A level I trauma centre experience. Int Orthop 2009;33(5):14251433. [http://dx.doi.org/10.1007/s00264-009-0746-9]

5. Tovar JA, Vazquez JJ. Management of chest trauma in children. Paediatr Respir Rev 2013;14(2):86-91. 5. Tovar JA, Vazquez J). Management of chest tra
[http://dx.doi.org/10.1016/j.prrv.2013.02.011]

6http://dx.doi.org/10.1016/j.prrv.2013.02.011] 6. Nakayama DK, Ramenofsky ML, Rowe MI. Chest injuries in
775. [http://dx.doi.org/10.1097/00000658-198912000-00013]

7. Ismail MF, al-Refaie RI. Chest trauma in children, single center experience. Arch Bronconeumol 2012;48(10):362-366. [http://dx.doi.org/10.1016/j.arbr.2012.07.007]

8. Balci AE, Kazez A, Eren S, Ayan E, Ozalp K, Eren MN. Blunt thoracic trauma in children: Review of 137 cases. Eur J Cardiothorac Surg 2004;26(2):387-392. [http://dx.doi.org/10.1016/j.ejcts.2004.04.024] 9. Rielly JP, Brandt ML, Mattox KL, Pokorny WJ. Thoracic trauma in children. J Trauma 1993;34(3):329331. [http://dx.doi.org/10.1097/00005373-199303000-00003]

10. Roux P, Fisher RM. Chest injuries in children: An analysis of 100 cases of blunt chest trauma from motor vehicle accidents. J Pediatr Surg 1992;27(5):551-555. [http://dx.doi.org/10.1016/00223468(92)90443-B]

11. Peclet MH, Newman KD, Eichelberger MR, Gotschall CS, Garcia VF, Bowman LM. Thoracic trauma in children: An indicator of increased mortality. J Pediatr Surg 1990;25(9):961-965; discussion 5-6. [http://dx.doi.org/10.1016/0022-3468(90)90238-5]

12. Road Traffic Accident Deaths in South Africa, 2001-2006: Evidence from Death Notification. Statistics South Africa, 2009

13. Van As AB, Millar AJ. From the pursuit of excellence to the quest for significance: Promotion of a Childsafe South Africa. S Afr Med J 2012;102(6):427-428.

14. Liman ST, Kuzucu A, Tastepe AI, Ulasan GN, Topcu S. Chest injury due to blunt trauma. Eur J Cardiothorac Surg 2003;23(3):374-378. [http://dx.doi.org/10.1016/s1010-7940(02)00813-8]

15. Tovar JA. The lung and pediatric trauma. Semin Pediatr Surg 2008;17(1):53-59. [http://dx.doi. org/10.1053/j.sempedsurg.2007.10.008]

16. Van Hoving DJ, Sinclair M, Wallis LA. Patterns of seatbelt use in different socioeconomic communities in the Cape Town metropole, South Africa. S Afr Med J 2013;103(9):628-631. [http://dx.doi. org/10.7196/SAMJ.7126]

17. Clancy K, Velopulos C, Bilaniuk JW, et al. Screening for blunt cardiac injury: An Eastern Association for the Surgery of Trauma practice management guideline. J Trauma Acute Care Surg 2012;73(5 Suppl 4):S301-S306. [http://dx.doi.org/10.1097/TA.0b013e318270193a]

18. Dowd MD, Krug S. Pediatric blunt cardiac injury: Epidemiology, clinical features, and diagnosis. Pediatric Emergency Medicine Collaborative Research Committee: Working Group on Blunt Cardiac Pediatric Emergency Medicine Collaborative Research Committee: Working Group on Blunt
Injury. J Trauma 1996;40(1):61-67. [http://dx.doi.org/10.1097/00005373-199601000-00012]

19. Allen GS, Cox CS Jr, Moore FA, Duke JH, Andrassy RJ. Pulmonary contusion: Are children different? J 9. Allen GS, Cox CS Jr, Moore FA, Duke JH, Andrassy RJ. Pulmonary contusion: Are childre
Am Coll Surg 1997;185(3):229-333. [http://dx.doi.org/10.1016/S1072-7515(97)00022-7]

20. Kleinman ME, Chameides L, Schexnayder SM, et al. 2010 American Heart Association Guidelines for Cardiopulmonary Resuscitation and Emergency Cardiovascular Care: Part 14: Pediatric Advanced Life Support. Circulation 2010;122:S876-S908. [http://dx.doi.org/10.1161/ CIRCULATIONAHA.110.971101]

Accepted 10 November 2014. 